\title{
Predictive values at risk of falling in physically active and no active elderly with Berg Balance Scale
}

\section{Valores preditivos para o risco de queda em idosos praticantes e não praticantes de atividade física por meio do uso da Escala de Equilíbrio de Berg}

Gilmar M. Santos', Ana C. S. Souza², Janeisa F. Virtuoso³, Graziela M. S. Tavares4, Giovana Z. Mazo

\begin{abstract}
Background: The consequences of falls are a major cause of autonomy and independence loss among the elderly. In this context, the Berg Balance Scale (BBS) has been widely used to detect the risk of falls in elderly. Objective: To evaluate the predictive value of the BBS for fall risk in physically active and inactive elderly subjects. Methods: The sample included 188 older adults with a mean age of $66( \pm 9)$ years. Of these, 91 participated in a regular physical activity program and 96 did not. We analyzed the cut-off scores of 45 , 47, 49, 51 and 53 in both groups regarding the sensitivity (S), specificity (Sp), positive predictive value (PPV) and negative predictive value (NPV) of the test, including the positive likelihood ratio (PLR) and negative likelihood ratio (RVN) for diagnosing the risk of falls. Results: The mean BBS score was 54.7 in physically active subjects and 50.8 in inactive subjects, which was statistically significant $(\rho=0.001)$. The best cut-off was a score of 49 for physically inactive subjects, with a sensitivity of $91 \%$ and a specificity of $92 \%$. On the other hand, the BBS had low sensitivity (from 0 to 15\%) and high specificity (between $83 \%$ and $100 \%$ ) for physically active subjects at the cut-off points analyzed. Conclusion: The scale did not achieve sufficient sensitivity to individual differences among physically active older people with higher levels of functional balance ability.
\end{abstract}

Keywords: Aged; postural balance; falls; physical activity; sensitivity; specificity.

\section{Resumo}

Contextualização: Umas das principais causas da perda da autonomia e independência do idoso são as consequências geradas pelas quedas. Nesse contexto, a Escala de Equilíbrio de Berg (EEB) vem sendo amplamente utilizada para detectar o risco de queda em idosos. Objetivo: Analisar os valores preditivos para o risco de queda em idosos praticantes e não-praticantes de atividade física por meio do uso da EEB. Métodos: Participaram 188 idosos, com média de idade de $66( \pm 9)$ anos. Desses, 91 participavam de projetos de atividades físicas, e 96 não praticavam atividade física regularmente. Foram analisados os pontos de corte 45, 47, 49, 51 e 53 em ambos os grupos, quanto à sensibilidade (S), especificidade (E), valor preditivo positivo (VPP) e negativo (VPN) do teste, razão de verossimilhança positiva (RVP) e negativa (RVN) para diagnóstico do risco de queda. Resultados: Evidenciou-se que a média do escore da EEB nos praticantes de atividade física foi de 54,7 pontos; enquanto que, entre os não-praticantes, foi de 50,8, obtendo-se diferença significativa entre os grupos $(\rho=0,001)$. Nos sujeitos não-praticantes de atividade física, o melhor ponto de corte foi em 49 pontos, apresentando S de $91 \%$ e E de $92 \%$, enquanto a EEB apresentou baixa S, variando entre $0 \%$ e $15 \%$, e alta E, variando entre $83 \%$ e $100 \%$ nos sujeitos praticantes de atividade física regular nos pontos de corte analisados. Conclusão: A escala não alcançou $\mathrm{S}$ suficiente para diferenças individuais entre idosos com altos níveis de capacidade de equilíbrio dentre aqueles que praticam atividades físicas regularmente.

Palavras-chave: idoso; equilíbrio postural; quedas; atividade física; sensibilidade; especificidade.

Received: 21/01/2010 - Revised: 04/07/2010 - Accepted: 16/12/2010

\footnotetext{
'Physical Therapy Department, Universidade do Estado de Santa Catarina (UDESC), Florianopolis, SC, Brazil

${ }^{2}$ Instituto de Ensino Superior da Grande Florianopolis (IES), São José, SC, Brazil

${ }^{3}$ Physical Therapist

${ }^{4}$ Physical Therapy Department, Universidade Federal do Pampa (UNIPAMPA), Uruguaiana, RS, Brazil

${ }^{5}$ Department of Physical Education, UDESC

Correspondence to: Gilmar Moraes Santos, Rua Professor Bayer Filho, 125, Coqueiros, CEP 88080-300, Florianópolis, SC, Brasil, e-mail: gilmar.santos@udesc.br
} 


\section{Introduction $: \therefore$.}

According to the Brazilian Institute of Geography and Statistics (IBGE), in 2000 there were nearly 15 million Brazilians over 60 years old, or $8.6 \%$ of the population ${ }^{1}$. It is estimated that in the next 20 years, Brazil will have the sixth largest population of elderly people, with more than 30 million inhabitants over 60 years old, or almost $13 \%$ of the population ${ }^{1}$.

The consequences of falls are one of the main causes of autonomy and independence loss in this population ${ }^{2,3}$. Epidemiological studies have demonstrated that falls occur at least once a year in $32 \%$ of those aged 65 to 74 years, $35 \%$ of those between 75 and 84 and $51 \%$ of those over 85 years ${ }^{4}$. In Brazil, it is estimated that 20 to $30 \%$ of elderly people fall at least once a year ${ }^{2,3}$. Of these, 15 to $50 \%$ will be hospitalized or die in the following year ${ }^{4}$. According to the Brazilian National Health System/Ministry of Health database (DATASUS), between 1996 and 2005 approximately 24,645 elderly people died due to falls, which ranked as the third leading cause of mortality and the leading cause of hospital admission ${ }^{5}$.

Due to such considerations, there is a constant concern among health professionals to prevent and mitigate the consequences of falls in geriatric health. Thus, pursuant to the need for effective assessment of the elderly population, several instrument models have been developed for the early detection of those with the greatest risk of falls.

Functional clinical tests are among such models and have the advantage of being easy to apply, low cost and having results with more apparent therapeutic implications. The most widely used of these tests are the Berg Balance Scale (BBS), the Clinical Test of Sensory Integration and Balance (CTSIB), the Test of Functional Reach, the Tinetti Balance Scale and the Timed Up and Go Test (TUGT). Each of these tests assesses different factors related to balance, and each has its advantages and disadvantages ${ }^{6-9}$. However, it is of vital clinical importance to know the most suitable instrument for identifying the risk of falls in each specific population type.

The BBS has been widely used in research related to the balance of elderly people. However, some studies ${ }^{10,11}$ have reported that this instrument is unreliable for detecting the risk of falls among the elderly. Other studies ${ }^{6,12,13}$, on the other hand, recommend it or consider it the gold standard ${ }^{14-16}$. This study, therefore, aimed to analyze the predictive values of the BBS for fall risk among both physically active and inactive elderly people.

\section{Methods : : :}

This study was approved by the Ethics Committee on Human Research of the Universidade do Estado de Santa Catarina
(UDESC), Florianopolis, SC, Brazil, under protocol no 057/07 and was performed in accordance with Resolution 196/96 of the National Health Council for Human Research. All participants signed an informed consent statement.

This descriptive cross-sectional study selected individuals of both genders over 60 years old who either practiced some form of regular physical activity or not and who had no history of lowerlimb or spinal surgery in the previous 12 months, no musculoskeletal or neurological disorders of the vestibular or cerebellar systems that might interfere with or prevent the assessment of balance, did not use any type of device to help support their body weight (cane, crutch or walker) and who had no cognitive impairment according to the Mini Mental State Examination (MMSE) ${ }^{17}$.

The sample consisted of 188 elderly people, 91 enrolled in physical activity projects organized by the UDESC Geriatrics Research Group (GETI) and 96 sedentary elderly people who frequented local community groups in the Florianopolis region.

The subjects were initially asked about their age, physical activity level, associated diseases and any falls they had suffered in the previous 12 months. The verification of falls via self-reporting may lead to bias, especially when the recall period is too long. However, other studies ${ }^{6,13,17-19}$ that adopted the parameters were taken as a basis.

After this step, the assessment of functional mobility and balance with the BBS was carried out.

The BBS assesses the dynamic and static balance of individuals and their risk of falls, considering the environmental influence on function. It assesses balance performance via 14 tasks, including the individual's ability to sit, stand, reach, turn $360^{\circ}$, look over his shoulders, stand on one foot, and place one foot on a stair or stool while standing unsupported. It has a maximum score of 56 points and a minimum of 0 ; each task has five possible scores ranging from 0 to 4 points. The BBS was translated into Portuguese and culturally adapted for use in Brazil. The Brazilian version of the BBS showed high intra- and interater reliability (ICC 0.99 and 0.98, respectively), proving its usefulness in assessing the balance of elderly Brazilians ${ }^{20}$.

The materials used were: one chair with arm support whose seat was $42 \mathrm{~cm}$ high and whose back support was $62 \mathrm{~cm}$ high; another chair with neither arm nor back support that was $42 \mathrm{~cm}$ high; one 15-cm high step; one $150 \mathrm{~cm}$ measuring tape; one stopwatch and one $5 \mathrm{x} 11 \mathrm{~cm}$ box. During assessment, subjects were instructed to wear their normal shoes.

The study included six evaluators: three physical therapists and three physical therapy students in the sixth semester of their course. All evaluators were previously trained and had prior experience in balance analysis with the BBS in other studies.

A descriptive data analysis was conducted using frequency tables for categorical variables and measures of position and dispersion for continuous variables. 
The Mann-Whitney U-test was used for comparison between groups, since data was not normally distributed. The chi-square test was used to compare frequencies of qualitative variables between groups. A significance level of $5 \%(\rho=0.05)$ was used for all tests.

In order to clarify how the BBS's diagnostic accuracy was evaluated, Table 1 was created. In it, the words "current condition" and "non-current condition" identify individuals with and without selfreported falls. The terms "positive" and "negative" test result are related to the cutoff point at which all subjects with a BSS score less than or equal to the cutoff point were considered positive (i.e., at risk of falling) and those who had a BBS score higher than the cutoff point were considered negative (i.e., without risk of falling). The letters "a", "b" "c" and "d" were used to reference the cells in Table 2.

The BBS cutoff points were analyzed in both groups regarding sensitivity (S), specificity (SP), positive (PPV) and negative predictive value (NPV) of the test and positive (PLR) and negative likelihood ratio (NLR) of diagnosing the risk of falling ${ }^{10,13,21-23}$. The cutoff points used to detect fall risk in both groups were: 45, 47, 49, 51 and 53, and were based on studies by Berg et al. ${ }^{6}$, Shumway-Cook et al. ${ }^{12}$, Riddle and Stratford ${ }^{13}$ and Alzayer, Beninato and Portney ${ }^{21}$. The abbreviation, formula and purpose of each measure of quality are shown in Table 2.

\section{Results $:: \therefore$}

A sample of 188 elderly people with a mean age of $66( \pm 9)$ years, body mass of $71.1( \pm 14) \mathrm{kg}$, height of $1.56( \pm 0.08) \mathrm{m}$ and
Body Mass Index of $28.9( \pm 5.1) \mathrm{kg} / \mathrm{m}^{2}$ participated in this study (Table 3). The types of physical activity practiced by the group of active elderly people were water aerobics (62.6\%), swimming (29.7\%) and others such as gymnastics and walking (24.2\%). A total of $16.5 \%$ of the elderly people practiced more than one type. All classes were held twice a week for 50 minutes. The exercise was of moderate intensity, i.e., practitioners had to exert physical effort to carry it out and faster breathing was involved.

Among physically active subjects, 23 (25.2\%) self-reported a fall in the previous year, while in the inactive group, $37 \mathrm{did}$ so $(38.5 \%)$, which was a statistically significant difference $(\rho=0.02)$. The BBS scores in the active group ranged from 48 to 56 points $($ mean $=54.7)$. Among inactive subjects, scores varied from 30 to 56 points $($ mean $=50.8)$. The intergroup difference was significant $(\rho=0.001)$ (Table 4$)$.

The S and SP of the cutoff point 49 were $91 \%$ and $92 \%$, respectively, in the inactive group. However, in the active group, the $\mathrm{S}$ was low (5\%) for detecting the probability of a fall (Table 5).

With a score of less than or equal to 49 points, the majority $(86.5 \%)$ of inactive subjects showed a history of falls

Table 1. Composition of the validity indices adopted in the study.

\begin{tabular}{lcc}
\hline \multirow{2}{*}{ Test Result } & \multicolumn{2}{c}{ Historical of Fall } \\
& Current condition & Non-current condition \\
\hline Positive & True Positive (a) & False Positive (b) \\
\hline Negative & False Negative (c) & True Negative (d) \\
\hline
\end{tabular}

Table 2. Abbreviations, formulas and purpose of the quality measures: sensitivity, specificity, positive and negative predictive value, and positive and negative likelihood ratio.

\begin{tabular}{|c|c|c|c|}
\hline Measure & Symbol & Formula & Finality \\
\hline Sensitivity & S & $S=\frac{a}{(a+c)} \times 100=\%$ & $\begin{array}{l}\text { Measures the ability of the test to detect the occurrence of } \\
\text { the disease, in this case the fall, including individuals who } \\
\text { have suffered, i.e., how sensitive the test is. }\end{array}$ \\
\hline Specificity & SP & $S p=\frac{d}{(b+d)} x 100=\%$ & $\begin{array}{l}\text { The ability of the test to exclude individuals who do not have } \\
\text { the disease, in this case the fall, i.e., how specific the test is. }\end{array}$ \\
\hline Positive Predictive Value & PPV & $P P V=\frac{a}{(a+b)} \times 100=\%$ & $\begin{array}{l}\text { The probability there will be a self-reported fall if the BBS } \\
\text { was negative at a certain cutoff point. }\end{array}$ \\
\hline Negative Predictive Value & NPV & $N P V=\frac{d}{(c+d)} x 100=\%$ & $\begin{array}{l}\text { The probability that there will not be a self-reported fall if } \\
\text { the test was negative at a certain cutoff point. }\end{array}$ \\
\hline Positive Likelihood Ratio & PLR & $P L R=\frac{\frac{a}{(a+c)}}{\frac{b}{(b+d)}}$ & $\begin{array}{l}\text { The ratio of probability that a BBS cut-off point will be } \\
\text { positive if there is a self-reported fall, and the probability of } \\
\text { cutoff of BBS will be positive if there is no self-reported fall. }\end{array}$ \\
\hline Negative Likelihood Ratio & NLR & $N L R=\frac{\frac{c}{(a+c)}}{\frac{d}{(b+d)}}$ & $\begin{array}{l}\text { The ratio of probability that a BBS cut-off point will be negative } \\
\text { if there is a self-reported fall, and the probability that a BBS cut- } \\
\text { off point will be negative if there is no self-reported fall. }\end{array}$ \\
\hline
\end{tabular}

$a=$ history of falling and positive test results, $b=$ no history of falling and positive test results, $c=$ history of falling and negative test results, $d=$ no history of falling out and negative test results. 
(positive test) and were classified as at risk of falling (PPV). However, only $13.5 \%$ of these individuals were wrongly classified as at risk of falling, which is considered to be a low error rate (Table 5).

Generally speaking, it can be said that, regardless of the studied cutoff point, the BBS had low S values for physically active elderly subjects ( $0 \%$ to $15 \%$ ). Thus, it appears that the test does not satisfactorily predict the risk of falling among active subjects. Among those with higher scores (48 to 56 points), a ceiling effect (when a test score reaches its upper limit) was found, demonstrating that the BBS is not a good clinical tool for identifying fall risk among physically active elderly people.

\section{Discussion $\because:$.}

The current literature features several tests for evaluating the balance, functional mobility and risk of falls in elderly people $^{6-9}$. However, the sensitivity and specificity of particular tests for detecting changes in balance and predisposition to falling are not clear for each population type.

Among the most widely used of these tests is the BBS, whose best cutoff point in this study was 49 for inactive elderly people. This point represented the best match between BBS score and selfreported history of falls, with a high S (91\%) for detecting those at risk of falling and a high SP (92\%) for identifying those not at risk.

However, for the physically active group, the BBS had a low S (5-15\%) for identifying those at risk of falling and a high SP (94-100\%) for detecting those who had not suffered falls. Thus, the BBS is not the best clinical tool for identifying the risk of falls in this population.

Similar to our results, an attempt to develop a predictive model of fall risk among community elderly with and without a history of falls by Shumway-Cook et al. ${ }^{12}$ also resulted in 49 points as the best cutoff point. The authors found that $77 \%$ of elderly people had a previous history of falls (S), and $86 \%$ did not (SP), concluding that this scale was sensitive enough to detect the risk of falls in the studied sample.

Tabela 3. Characterization of physically active and inactive elderly subjects.

\begin{tabular}{lccc}
\hline & Practitioners $\bar{x}(\delta)$ & Non- Practitioners $\bar{x}(\delta)$ & $\rho$ \\
\hline Age (years) & $68.05( \pm 7.1)$ & $64.75( \pm 8.2)$ & 0.14 \\
\hline Body mass $(\mathrm{Kg})$ & $68.27( \pm 11.9)$ & $74.28( \pm 15.5)$ & $0.01^{\star}$ \\
\hline Height $(\mathrm{m})$ & $1.56(0.06)$ & $1.57( \pm 0.09)$ & 0.11 \\
\hline Body mass index $\left(\mathrm{Kg} / \mathrm{m}^{2}\right)$ & $28.08( \pm 4.3)$ & $29.83( \pm 5.8)$ & 0.09 \\
\hline Gender & & & \\
\hline Male & $19(20.8 \%)$ & $22(22.9 \%)$ & \multirow{2}{*}{0.74} \\
\hline Female & $72(79.2 \%)$ & $74(77.1 \%)$ & 0.40 \\
\hline Presence of self-reported morbidity** & $65(71.4 \%)$ & $61(63.5 \%)$ & $0.00^{*}$ \\
\hline Circulatory & $40(43.9 \%)$ & $29(30.2 \%)$ & $0.00^{*}$ \\
\hline Musculoskeletal and/or tissue & $29(31.8 \%)$ & $34(35.4 \%)$ & 0.56 \\
\hline Endocrine and/or metabolic & $20(21.9 \%)$ & $14(14.5 \%)$ & -- \\
\hline Other & $11(12.0 \%)$ & $32(33.3 \%)$ & \\
\hline
\end{tabular}

${ }^{*} \rho<0.05$; **frequencies and percentages.

Table 4. Score of the Berg Balance Scale between the elderly groups practitioners and non-practitioners of physical activities in relation to history of falling.

\begin{tabular}{lccccc}
\hline \multirow{2}{*}{ Score } & \multicolumn{2}{c}{ Practitioners } & \multicolumn{2}{c}{ Non-Practitioners } \\
& With a History of falling & Without a history of falling & With a History of falling & Without a history of falling \\
\hline $30-40$ & 0 & 0 & 4 & 0 \\
\hline $41-45$ & 0 & 0 & 6 & 0 \\
\hline 46 & 0 & 0 & 5 & 0 \\
\hline 47 & 0 & 0 & 6 & 0 \\
\hline 48 & 1 & 1 & 3 & 2 \\
\hline 49 & 0 & 0 & 8 & 4 \\
\hline 50 & 0 & 1 & 1 & 10 \\
\hline 51 & 1 & 2 & 0 & 10 \\
\hline $52-53$ & 1 & 8 & 1 & 32 \\
\hline 56 & 17 & 59 & & $50.8( \pm 4.98)$ \\
\hline $\bar{x}$ (SD) & & $54.7( \pm 1.74)$ & & & \\
\hline $\bar{x}$
\end{tabular}

$\bar{x}=$ mean; $\mathrm{SD}=$ standard deviation. 
Muir et al. ${ }^{10}$, who analyzed the S and SP of the BBS for predicting falls in independent elderly people with no neurological deficits over one year, commented that the S of different cutoff points analyzed ranged from 25 to $42 \%$ and the SP was between $86 \%$ and $87 \%$. These same authors reported that the high cutoff value required to optimize the $\mathrm{S}$ in each category of falls in elderly people indicates that the impairment of balance by itself does not define the increased risk of falls and that falls are common among elderly people with scores above 45 points.

Riddle and Stratford ${ }^{13}$ reported that the best BBS cutoff was 50 points, resulting in $85 \%$ and $73 \%$ for S and SP, respectively. At a 55point cutoff, they found a high S of $97 \%$, but a very low SP of $26 \%$.

In the original study by Berg et al. ${ }^{6}$, the cutoff point of 45 was used to calculate the probability of a relative risk of falls as a demonstration of predictive validity. Corroborating this, Holbein-Jenny et al. ${ }^{24}$ also demonstrated that the best cutoff was 45. However, both the present and previous studies ${ }^{11-13}$ have declined to recommend this value as a cutoff point for BBS.

There is considerable disagreement in the literature concerning the BBS cutoff point. This can be explained by differences in study samples, e.g., elderly nursing home residents who use assistive devices for walking and have neurological deficits show remarkable differences with those without such deficits and who reside in their own home. However, all studies agreed that the lower the performance by elderly individuals on the BBS, the higher the likelihood of falls. With this in mind, it is of great importance that the cutoff point for this test be adapted to each type of population, since neurological, orthopedic and visual factors, lifestyle and physical activity level, etc., directly influence BBS performance.

In this study, the sedentary group showed a high NPV, indicating that $94.9 \%$ of elderly people with scores above 49 points were classified as having no fall risk. Thus, $4.1 \%$ of the subjects who scored over 49 points on the BBS were false negatives and classified as being at risk of falling, which is a very low error rate. The PPV of this sample showed that $86.5 \%$ of the individuals with a score below 49 points self-reported a fall and were classified as being at high risk of fall; however, $13.5 \%$ of those who did not self-report a fall were false positives, which was an acceptable error rate for this type of instrument.

Moreover, the PLR was 10.2, i.e., an elderly person with a score below 49 has about ten times more chance of falling than someone with a higher score. The NLR was 0.09 , indicating that someone with score above 49 points is 0.09 times more likely to fall. These data confirm that the best cutoff point for the sample of inactive elderly people was 49 points.

However, the BBS showed a PPV ranging between 0 and $50 \%$ for physically active elderly individuals, which is considered too low to classify those who self-report a fall at the analyzed cutoff points. Consequently, the PLR was very low, ranging between 0.88 and 1.04 , which confirms that the BBS was not able to predict falls in this population. In this context, Muir et al. ${ }^{10}$ reported that a PLR of approximately 1 indicates that the instrument is not sensitive enough to predict falls, and thus did not recommended its application.

Riddle and Stratford ${ }^{13}$ consider 50 the best cutoff point with a PPV of 57\%, an NPV of 92\%, a PLR of 3.1 and an NLR of 0.2. At this cutoff point, individuals with scores $\leq 50$ points were three times more likely to suffer falls than those who scored over 50 points, which represents a 0.2 times higher chance of falling. These authors concluded that despite the heterogeneity of the sample in their study, the BBS was considered sensitive.

Muir et al. ${ }^{10}$ reported that a cutoff point of 54 had an S between 61 and $62 \%$ and an SP between 51 and 53\% for elderly individuals with no history of falls and for those whose falls had resulted in injury, respectively. A cutoff point of 53 resulted in an S of $69 \%$, an SP of $57 \%$ and a very low PLR (approximately 1) in elderly people with multiple falls. Thus, the authors suggested that the use of the BBS to identify those at high risk of falling should be discouraged because it was not able to identify most of the elderly people who had suffered falls. The predictive validity of this scale in elderly people with a history of multiple falls is higher than for those without falls or those who have had a single fall, and the likelihood ratio demonstrated an increased risk of falls throughout the entire score range.

Table 5. Sensitivity, specificity, positive predictive value, negative predictive value, positive likelihood ratio and negative likelihood ratio for BBS cutoff points among physically active and inactive elderly subjects.

\begin{tabular}{|c|c|c|c|c|c|c|c|c|c|c|c|c|}
\hline \multirow{2}{*}{ Cutoff Point } & \multicolumn{6}{|c|}{ Physically active } & \multicolumn{6}{|c|}{ Physically inactive } \\
\hline & $S$ & $\mathrm{Sp}$ & PPV & NPV & PLR & NLR & $S$ & Sp & PPV & NPV & PLR & NLR \\
\hline 45 & $0 \%$ & $100 \%$ & 0 & $78 \%$ & 1 & 0 & $29 \%$ & $100 \%$ & $100 \%$ & $70.9 \%$ & 1.4 & 0 \\
\hline 47 & $0 \%$ & $100 \%$ & 0 & $78 \%$ & 1 & 0 & $60 \%$ & $100 \%$ & $100 \%$ & $81.3 \%$ & 2.5 & 0 \\
\hline 49 & $5 \%$ & $99 \%$ & $50 \%$ & $78.7 \%$ & 1.04 & 0.2 & $91 \%$ & $92 \%$ & $86.5 \%$ & $94.9 \%$ & 10.2 & 0.09 \\
\hline 51 & $10 \%$ & $94 \%$ & $25 \%$ & $78.8 \%$ & 1.04 & 0.6 & $94 \%$ & $69 \%$ & $78.6 \%$ & $95.5 \%$ & 11.5 & 0.22 \\
\hline 53 & $15 \%$ & $83 \%$ & $20 \%$ & $89.4 \%$ & 0.88 & 1.02 & $97 \%$ & $52 \%$ & $54 \%$ & $97 \%$ & 2.02 & 0.06 \\
\hline
\end{tabular}

$\mathrm{S}=$ sensitivity; $\mathrm{Sp}=$ =specificity; PPV=positive predictive value; NPV=negative predictive value; PLR=positive likelihood ratio; NLR=negative likelihood ratio 
Bogle, Thorbahn and Newton ${ }^{11}$ reported that the level of physical activity seems not to influence performance on the BBS, which disagrees with the results of the present study. However, these authors explain their result as being due to the methodology used to classify the level of physical activity, since the scoring systems involved may not have been sufficiently sensitive to variations in individual activity patterns. Moreover, these same authors reported that the performance of daily activities contributes $43 \%$ to BBS performance scores. Perracini and $\operatorname{Ramos}^{3}$, Yap et al. ${ }^{25}$ and Rosa et al. ${ }^{26}$ all demonstrated a strong association between functional status and the occurrence of falls, suggesting that the loss of functional capacity seems to have a role in the multifactorial interaction that leads to falls, which calls for further investigation.

According to the literature, physical activity is the primary means of promoting geriatric health and it has been proposed as an effective intervention for preventing falls ${ }^{27,28}$. Its benefits have been widely studied ${ }^{29-31}$, and include improved functional capacity, balance, strength, coordination and speed of movement, which thereby contributes to greater security and fall prevention. However, it has been observed that even with regular physical activity, there is still a significant proportion of elderly people who fall (25.2\%), which suggests that the intensity of physical exercise may be important for reducing this prevalence.

Furthermore, the higher number of musculoskeletal disorders among the inactive elderly may justify the low BBS values, although these findings reiterate the importance both of physical activity and the need to develop better balance for fall prevention. Likewise, physical activity can lead to significant differences in body mass, which are not necessarily apparent in body mass index results.

Brauer, Burns and Galley ${ }^{32}$, who assessed the balance of 100 healthy elderly women with a mean age of $73.0 \pm 5.0$ years, reported that the BBS results indicated a ceiling effect for both the group with a history of falls and the group without one. This means that the BBS could not detect a risk of falling in this population. The same phenomenon was observed by Newton ${ }^{33}$, who evaluated 251 community-dwelling older adults with a mean age of 74.0 7.0 years and who suggested that modifications should be made to the BBS when it is applied to active elderly people $e^{33,34}$.

Based on the results of both this study and the above-cited studies, a cutoff of 49 points for inactive older adults showed an excellent S, SP, PPV and NPV, PLR and NLR, indicating that this scale is sensitive to individual differences in the sample, thus warranting its implementation. However, the BBS was not sensitive for active elderly people, resulting in a poor S, SP, PPV and NPV, PLR and NLR due to the ceiling effect observed in the sample. The BBS, therefore, is insensitive to individual differences among active elderly individuals with very high levels of balance ability, and should not be recommended for this population.

The use of other instruments, such as the Timed Up and Go, Speed Gait and Dynamic Gait Index may be more useful for identifying the risk of falls in physically active elderly people.

Despite the cross-sectional design, we believe that the findings of this study can significantly contribute to the clinical practice of professionals who deal with the elderly population. A suggestion for future studies would be longitudinal follow-up that could accurately identify the occurrence of falls among elderly people.

\section{References: : :}

1. IBGE (Instituto Brasileiro de Geografia e Estatística). Perfil dos Idosos Responsáveis pelos Domicílios. 2002. Disponível em: http://www.ibge.gov.br/home/presidencia/ noticias/25072002pidoso.shtm

2. Silvestre JA, Costa Neto MM. Abordagem do idoso em programas de saúde da família. Cad Saúde Pública. 2003;19(3):839-47.

3. Perracini MR, Ramos LR. Fatores associados a quedas em uma coorte de idosos residentes na comunidade. Rev Saúde Pública. 2002;36(6):709-16.

4. Baraff LJ, Della Penna R, Williams N, Sanders A. Practice guideline for the ED Management of falls in community - dwelling elderly persons. Ann Emerg Med. 1997;30(4):480-9.

5. Alves Jr ED. Analecto Treinamento PREV-Quedas. Rio de Janeiro: SESI-RJ; 2009.

6. Berg KO, Maki BE, Williams JI, Holliday PJ, Wood-Dauphinee SL. Clinical and laboratory measures of postural balance in an elderly population. Arch Phys Med Rehabil. 1992;73(11):1073-80.

7. Chiu AY, Au-Yeung SS, Lo SK. A comparison of four functional tests in discriminating fallers from non-fallers in older people. Disabil Rehabil. 2003;25(1):45-50.

8. Cho CY, Kamen G. Detecting balance deficits in frequent fallers using clinical and quantitative evaluation tools. J Am Geriatr Soc. 1998;46(4):426-30.

9. Nakamura DM, Holm MB, Wilson A. Measures of balance and fear of falling in the elderly: a review. Phys Occup Ther Geriatr. 1999;15(4):17-32.
10. Muir SW, Berg K, Chesworth B, Speechley M. Use of the Berg Balance Scale for predicting multiple falls in community-dwelling elderly people: a prospective study. Phys Ther. 2008;88(4):449-59.

11. Bogle Thorbahn LD, Newton RA. Use of the Berg Balance Test to predict falls in elderly persons Phys Ther. 1996;76(6):576-83.

12. Shumway-Cook A, Baldwin M, Polissar NL, Gruber W. Predicting the Probability for Falls in Community-Dwelling Older Adults. Phys Ther.1997;77(8):812-9.

13. Riddle DL, Stratford PW. Interpreting validity indexes for diagnostic tests: an illustration using the Berg balance test. Phys Ther. 1999;79(10):939-48

14. Southard V, Dave M, Davis MG, Blanco J, Hofferber A. The Multipe Task test as a predictor of falls in older adults. Gait Posture. 2005;22(4):351-5.

15. Whitney SL, Poole JL, Cass SP. A review of balance instruments for older adults. Am J Occup Ther. 1998;52(8):666-71.

16. Tyson SF, DeSouza LH. Reliability and validity of functional balance tests post stroke. Clin Rehabil. 2004;18(8):916-23.

17. Lourenço RA, Veras RP. Mini-Exame do Estado Mental: características psicométricas em idosos ambulatoriais. Rev Saúde Pública. 2006;40(4):712-9.

18. Bishop MD, Patterson TS, Romero S, Light KE. Improved fall-related efficacy in older adults related to changes in dynamic gait ability. Phys Ther. 2010;90(11):1598-606. 
19. Wennie Huang WN, Perera S, VanSwearingen J, Studenski S. Performance measures predict onset of activity of daily living difficulty in community-dwelling older adults. J Am Geriatr Soc. 2010;58(5):844-52.

20. Miyamoto ST, Lombardi Jr I, Berg KO, Ramos LR, Natour J. Brazilian version of the Berg balance scale. Braz J Med Biol Res. 2004;37(9):1411-21.

21. Alzayer L, Beninato M, Portney LG. The accuracy of individual Berg Balance Scale items compared with the total Berg score for classifying people with chronic stroke according to fall history. J Neurol Phys Ther. 2009;33(3):136-43.

22. Beninato M, Portney LG, Sullivan PE. Using the International Classification of Functioning, Disability and Health as a framework to examine the association between falls and clinical assessment tools in people with stroke. Phys Ther. 2009;89(8):816-25.

23. Dibble LE, Lange M. Pedicting falls in individuals with Parkinson disease: a reconsideration of clinical balance measures. J Neurol Phys Ther. 2006;30(2):60-7.

24. Holbein-Jenny M, Billek-Sawhney B, Beckman E, Smith T. Balance in personal care home residents: A comparasion of the Berg Balance Scale, the Multi-Directional Reach Test, and the Activities-Specific Balance Confidence Scale. J Geriatr Phys Ther. 2005;28(2):48-53.

25. Yap LK, Au SY, Ang YH, Ee CH. Nursing Home Falls: A Local Perspective. Ann Acad Med Singapore. 2003,32(6):795-800.
26. Rosa TEC, Benício MHD, Latorre MRDO, Ramos LR. Fatores determinantes da capacidade funcional entre idosos. Rev Saúde Pública. 2003;37(1):40-8.

27. Ramos BMB. Influências de um programa de atividade física no controle do equilíbrio de idosos [monografia]. São Paulo: USP; 2003.

28. Ribeiro TV. Estudo do equilíbrio estático e dinâmico em indivíduos idosos. [dissertação]. Porto: Faculdade de Desporto da Universidade do Posto; 2009.

29. Matsudo SMM. Envelhecimento e atividade física. Londrina: Midiograf; 2001.

30. Spirduso WW. Dimensões físicas do envelhecimento. Barueri, SP: Manole; 2005.

31. Gallahue DL, Ozmun JC. Compreendendo o desenvolvimento motor: bebês, crianças, adolescentes e adultos. $3^{\mathrm{a}}$ ed. São Paulo: Phorte; 2005

32. Brauer SG, Burns YR, Galley P. A prospective study of laboratory and clinical measures of postural stability to predict community-dwelling fallers. J Gerontol A Biol Sci Med Sci. 2000;55(8):M469-76.

33. Newton RA. Balance screening of an Inner city older adult population. Arch Phys Med Rehabil. 1997;78(6):587-91.

34. Langley FA, Mackintosh SFH. Functional balance assessment of older community dwelling adults: a systematic review of the literature. IJAHSP. 2007;5(4):1-11. 